\title{
Picoline Compound
}

National Cancer Institute

\section{Source}

National Cancer Institute. Picoline Compound. NCI Thesaurus. Code C746.

Any of a group of isomeric compounds that are monomethyl derivatives of pyridines derived from coal tar, horse urine, and bone oil. 